\title{
RNAi-mediated abrogation of cathepsin B and MMP-9 gene expression in a malignant meningioma cell line leads to decreased tumor growth, invasion and angiogenesis
}

\author{
PADMAJA TUMMALAPALLI ${ }^{1}$, DANIEL SPOMAR ${ }^{2}$, CHRISTOPHER S. GONDI $^{1}$, \\ WILLIAM C. OLIVERO ${ }^{2}$, MEENA GUJRATI ${ }^{3}$, DZUNG H. DINH ${ }^{2}$ and JASTI S. RAO ${ }^{1,2}$ \\ Departments of ${ }^{1}$ Cancer Biology and Pharmacology, ${ }^{2}$ Neurosurgery and ${ }^{3}$ Pathology, \\ University of Illinois College of Medicine at Peoria, Peoria, IL, USA
}

Received May 14, 2007; Accepted June 28, 2007

\begin{abstract}
Malignant meningiomas are highly aggressive and frequently recur after surgical resection of the tumor. Earlier studies have reported that the cysteine protease cathepsin B and the matrix metalloproteinase MMP-9 play important roles in tumor progression. In the present study, we made an attempt to evaluate the roles of these proteases in the malignant meningioma tumor microenvironment and determined the effectiveness of using single or bicistronic siRNA constructs for cathepsin B and MMP-9, in both in vitro and in vivo models. Transfection of a plasmid vector expressing doublestranded RNA for cathepsin B and MMP-9 significantly inhibited mRNA and protein levels of cathepsin B and MMP-9. The migration and invasion of meningioma cells were decreased after treatment with single or bicistronic siRNA constructs for cathepsin B and MMP-9 compared to controls and vector controls. Inhibition of angiogenesis was observed when the cells were transfected with single or bicistronic constructs for cathepsin B and MMP-9, when compared to controls or empty vector controls. Our study revealed that abrogation of cathepsin B and MMP-9 expression decreased the activation of major proteins involved in MAP kinase and PI3 kinase pathways indicating that targeting these proteases may hinder intracellular signaling and thus decrease
\end{abstract}

Correspondence to: Dr J.S. Rao, Department of Cancer Biology and Pharmacology, University of Illinois College of Medicine at Peoria, One Illini Drive, Peoria, IL 61605, USA

E-mail: jsrao@uic.edu

Abbreviations: uPA[R], urokinase-type plasminogen activator [receptor]; CMV, cytomegalovirus; PCR, polymerase chain reaction; PBS, phosphate-buffered saline; FITC, fluoresceine-5-isothiocyanate; DiI, 1'-dioctadecyl-3,3,3',3'-tetramethylindocarbocyanineperchlorate; DiO, 3,3'-dioctadecyloxacarbocyanine perchlorate; GFP, green fluorescent protein; ECM, extracellular matrix; EGFR, epidermal growth factor receptor; VEGF, vascular endothelial growth factor; HMEC, human endothelial cells

Key words: cathepsin B, tumor, invasion, angiogenesis cell survival and proliferation in malignant meningiomas. In addition to the in vitro evidence, we observed a significant regression of pre-established orthotopic tumors after treatment with RNAi plasmid vectors targeting cathepsin B and MMP-9. Furthermore, these observations demonstrate that the simultaneous RNAi-mediated targeting of cathepsin B and MMP-9 has potential application for the treatment of human meningiomas.

\section{Introduction}

Meningiomas are the most commonly occurring intracranial tumors and account for approximately $15-20 \%$ of central nervous system tumors. These tumors arise from the meninges, which are the membranes that surround the brain and spinal cord. Meningiomas are reported to develop typically from the meningothelial cells found in the arachnoid villi of the meninges. In the majority of cases, meningiomas develop in the cerebral hemispheres of the brain. However, occurrence of meningiomas in other parts of the brain and spinal cord have also been reported. Meningiomas are classified by WHO into 11 different categories based on their cell type of origin, but these tumors depending on their aggressiveness can be broadly classified into three groups: WHO Grade I (benign), WHO Grade II (atypical) and WHO Grade III anaplastic (malignant) meningiomas. Ninety percent of meningiomas are benign- relatively non-aggressive and easily treated with surgery with a low rate of recurrence. However, when benign meningiomas occur in inoperable locations, these tumors can cause serious problems and may occasionally recur. Approximately 3-7\% of meningiomas progress to atypical or anaplastic tumors. About $2 \%$ of meningiomas present as malignant tumors. These malignant tumors are difficult to cure and show a high rate of recurrence $(78 \%)$. Also, though very rare, malignant meningiomas can metastasize into other organs such as the lungs (1). Tumor progression mainly depends on the ability of tumor cells to overcome histological barriers including the basement membrane, the interstitial stroma for invasion into surrounding tissue, rapid cell proliferation and stimulation of release of growth factors that favor tumor growth. Earlier studies have shown that during tumorigenesis, various proteolytic cascades consisting 
of enzymes such as cysteine proteases, metalloproteinases (MMPs) and serine proteases act in a synchronized manner and aid in tumor growth, invasion into surrounding tissue, metastasis, etc. (2-5).

Tumorigenesis is a complex process that involves equal contribution from extracellular as well as intracellular proteolytic events (6). Cathepsin B is a lysosomal acid hydrolase composed of a heavy chain of 25-26 kDa and a light chain of $5 \mathrm{kDa}$ and functions as both a exopeptidase and endopeptidase. Excessive secretion and active involvement of cathepsin B has been observed in several disease conditions such as arthritis, multiple sclerosis and cancer. In these disease conditions, cathepsin B has been implicated in the degradation of the extracellular matrix (ECM) either in secreted form in the extracellular space or attached to the cell surface (6). Additionally, cathepsin B has been reported to be involved in this process directly through degradation of the extracellular matrix components such as fibronectin, type I and type IV collagen, laminin, and indirectly through activation of metalloproteinases, soluble and receptor-bound uPA $(7,8)$. Elevated levels of cathepsin B expression have been reported at the mRNA level in prostate cancer (9), colorectal cancer (10), gliomas $(11,12)$ and melanomas $(13)$. Increased expression and activity of cathepsin B has also been reported in various types of cancers $(14,15)$. The poor prognosis associated with excessive secretion of cathepsin $\mathrm{B}$ has been reported in patients suffering from colon cancer (16) and ovarian cancer (17). Furthermore, earlier studies have shown that cathepsin B is not only secreted at a higher degree, but also localized at the invasion front of the tumor (4), thereby providing further support for its role in ECM degradation. Cathepsin B is also known to be involved in intracellular proteolysis events and activation of signaling pathways (18). The elevated expression of cathepsin B and gelatinase B (MMP-9) and localization on the plasma membrane of cells at the invasion front have been reported in bone metastatic tissue (19) and chordoma (5).

During tumorigenesis, tumor cells are challenged with several physiological barriers that cells must overcome through modification of regulatory pathways or through altered expression of some proteins that enable cell survival. Matrix metalloproteinases aid tumor cells in extracellular matrix degradation, invasion, migration and metastasis. MMP-9 (also known as gelatinase B) is a $92-\mathrm{kDa}$ matrix metalloproteinase that is actively involved in the degradation of the extracellular matrix in the tumor microenvironment. Elevated expression of MMP-9 has been reported in several cancer types $(20,21)$. An inverse correlation between increased MMP-9 expression and disease prognosis has been reported in renal cell carcinoma (22). In addition, matrix metalloproteinases are specifically reported to aid in angiogenesis during tumor progression. In general, MMP-9 is thought to play a major role in two important aspects of tumor progression - angiogenesis and vasculogenesis (23). Our previous results demonstrated significantly higher levels of cathepsin B and MMP-9 during the progression of malignant meningiomas.

All these findings focus on the crucial roles of cathepsin B and MMP-9 in a tumor environment both individually and in combination with other proteases. Hence, it would be of great interest to target these proteins and determine the resulting therapeutic efficiency for cancer treatment. Blockage of expression through neutralizing antibodies (24), specific inhibitors (25) and antisense oligonucleotides (26) proved useful in suppression of these proteins in various cancer scenarios. Recently, RNA interference (RNAi) has emerged as a novel, highly efficient method for silencing of gene expression. RNAi technology consists of post-transcriptional silencing of gene expression through double-stranded RNA (dsRNA) with a sequence complementary to targeted gene. Intracellular machinery comprising Drosha and Dicer (a cellular ribonuclease III) proteins generate small hairpin RNA (shRNA) of about 21-23 nucleotides, which then mediate gene silencing by degradation/blocking of translation of the target mRNA (27). In the present study, we developed plasmid vectors that express small hairpin RNA (shRNA) targeting cathepsin B and MMP-9 individually, and a bicistronic plasmid vector that expressed shRNA targeting cathepsin B and MMP-9 simultaneously. All the plasmids expressed under the control of the human cytomegalovirus (CMV) promoter.

The RNAi plasmid constructs for these molecules subdued expression of the targeted proteins both at the mRNA and protein levels. Functional analysis following silencing of these proteins revealed that abrogation of the expression of these proteins led to decreases in tumor cell proliferation, invasion and angiogenesis. Analysis of downstream signaling pathways also revealed a positive response favoring tumor regression. These results indicate that targeting these proteins through RNAi vectors might present a novel method for the treatment of malignant meningiomas through gene therapy.

\section{Materials and methods}

Construction of siRNA plasmid vectors targeting cathepsin B and MMP-9. Vectors expressing shRNA for cathepsin B (pCB) and MMP-9 (pM) were constructed using pcDNA3 plasmids as described previously by our group (28). Along with single constructs expressing cathepsin $\mathrm{B}(\mathrm{pCB})$ and MMP-9 (pM), a bicistronic construct expressing shRNA for both cathepsin B and MMP-9 (pMC) was also constructed using a pcDNA3 vector. All the vectors were expressed under the control of a CMV promoter (28).

Cell culture and transfection conditions. We used the human meningioma cell line IOMM-Lee for the present study. The cell line was kindly provided by Dr Ian McCutcheon (U.T. M.D. Anderson Cancer Center, Houston, TX). The IOMM-Lee cell line was established from a recurrent primary intraosseus malignant meningioma of the skull. The cells were maintained in Dulbecco's modified Eagle's medium (Mediatech, Herndon, VA) supplemented with $10 \%$ fetal bovine serum, $100 \mu \mathrm{g} / \mathrm{ml}$ streptomycin and $100 \mathrm{U} / \mathrm{ml}$ penicillin (Invitrogen, Carlsbad, $\mathrm{CA}$ ) in a humidified atmosphere containing $5 \% \mathrm{CO}_{2}$ at $37^{\circ} \mathrm{C}$. IOMM-Lee cells were transfected with $\mathrm{pSV}, \mathrm{pCB}, \mathrm{pM}$ and pMC using lipofectamine reagent (Invitrogen) following manufacturer's instructions. Transfected cells were maintained in serum-containing media for $48 \mathrm{~h}$ before further use in various procedures. To study in situ expression of proteins, the cells were grown in Lab-Tek II chamber slides (Nalge Nunc International, Naperville, IL). 
Reverse transcription-PCR analysis of downregulation of mRNA for UPAR and MMP-9 following transfection with $p S V, p C B, p M$ and $p M C$. IOMM-Lee cells were transfected with $\mathrm{pSV}, \mathrm{pCB}, \mathrm{pM}$ and $\mathrm{pMC}$ shRNA plasmids following manufacturer's protocol. Untreated cells were maintained under similar conditions to serve as the control (mock). After a 48-h incubation period, total RNA was extracted from the cells following standard protocol. RNA was DNase-treated and reverse transcription reaction was set up using $\mathrm{RT}$ reaction mix (Invitrogen). The resultant cDNA was then used for PCR using primers for cathepsin B, MMP-9 and GAPDH.

Gelatin zymography. PMA-induced MMP-9 expression levels after RNAi-mediated downregulation of cathepsin B and MMP-9 were analyzed using gelatin zymography. IOMM-Lee cells were transfected with $\mathrm{pSV}, \mathrm{pCB}, \mathrm{pM}$ and pMC. Untreated cells were also cultured to serve as the control (mock). After a 24-h incubation period, serum-containing media were replaced with serum-free media and the cells were stimulated with 100 nM PMA. Conditioned media were collected from the cells after further incubation for $24 \mathrm{~h}$ and centrifuged to remove cellular debris. Equal amounts of protein $(40 \mu \mathrm{g})$ were subjected to electrophoresis on $10 \%$ SDS gels containing gelatin $(0.5 \mathrm{mg} / \mathrm{ml})$. Gels were stained with amido black (Sigma Aldrich, St. Louis, MO) and gelatinase activity of MMP-9 was visualized as clear bands on a dark blue background at areas corresponding to the molecular weight of the protein.

Western blot analysis. Forty-eight hours following transfection with $\mathrm{pSV}, \mathrm{pCB}, \mathrm{pM}$ and $\mathrm{pMC}$, protein extracts were obtained from the IOMM-Lee cells using a Tris-buffered lysis (Trisbuffered saline, $20 \mathrm{mM}$ EDTA, 0.1\% Triton X-100). Cell lysates were also collected from untreated cells that were cultured and maintained under similar conditions (mock). Protein concentration was determined using a bicinchoninic acid procedure (Pierce, Rockford, IL). Equal amounts of protein were then subjected to SDS-PAGE using gels with appropriate percentage of acrylamide followed by transfer of protein to polyvinylidene difluoride membranes (Bio-Rad, Hercules, CA). Membranes were then blocked in 5\% non-fat dry milk in phosphate-buffered saline (PBS), incubated with primary antibodies in blocking solution (1:1000 dilution) for either $2 \mathrm{~h}$ or overnight at $4^{\circ} \mathrm{C}$ as required. Membranes were then washed twice with T-PBS [Tween-20 (0.1\%), phosphate-buffered solution] for 15-min intervals. Horseradish peroxidase-conjugated secondary antibodies (Biomeda, Burlingame, CA) were used at a 1:2000 concentration and the membranes were developed following an enhanced chemiluminescence protocol (Amersham Biosciences, Piscataway, $\mathrm{NJ}$ ). The membranes were further probed for GAPDH, which was used as a loading control.

Cell proliferation assay. In vitro cell proliferation ability was determined as viable cell mass in both untreated IOMM-Lee cells and cells transfected with pSV, pM, pCB and pMC using Cell Titer $96^{\mathrm{TM}}$ colorimetric assay. IOMM-Lee cells $\left(5 \times 10^{3}\right)$ were cultured in triplicate in 96-well plates and transfected with $1 \mu \mathrm{g}$ of one of the shRNA expressing plasmid vectors following standard protocol. Untreated cells were also maintained under similar conditions to serve as the control (mock). Following transfection, the cells were maintained for different time intervals in serum-supplemented media. At each time-point $10 \mu 1$ freshly prepared MTT (3(4,5-dimehtylthiazol-2yl)-2,5-diphenyltetrazolium, Sigma Aldrich) reagent $(5 \mathrm{mg} / \mathrm{ml}$ sterile PBS) were added to each well and the cells were incubated further for $4 \mathrm{~h}$. The cells were then treated with the detergent $(2 \mathrm{ml}$ isopropanol supplemented with $6.66 \mu 1$ concentrated $\mathrm{HCl}$ ), and mixed thoroughly for color development. $\mathrm{A}_{570}$ was measured using an ELISA plate reader and OD values were plotted against the respective time intervals. The reduction in cell proliferation following downregulation of cathepsin B and MMP-9 was quantified as the decrease in the intensity of MTT-formazan (blue color measured calorimetrically at $570 \mathrm{~nm}$ ) at different time-intervals in the cells treated with plasmid vectors compared to the untreated cells (mock).

Immunofluorescence analysis of in situ protein expression. 8-well chamber slides were used to culture IOMM-Lee cells at a concentration of $5 \times 10^{3}$ per well. After a $24-\mathrm{h}$ incubation period, cells were transfected with $\mathrm{pSV}, \mathrm{pCB}, \mathrm{pM}$ and $\mathrm{pMC}$. Parental cells at similar concentration were also maintained to serve as the control (mock). Cells were maintained at $37^{\circ} \mathrm{C}$ for $48 \mathrm{~h}$, fixed with $3.7 \%$ formaldehyde and then blocked with $1 \%$ bovine serum albumin (BSA) for $1 \mathrm{~h}$ at room temperature. The slides were then incubated with primary antibodies diluted to a concentration of 1:200 in BSA overnight at $4{ }^{\circ} \mathrm{C}$. Slides were washed three times with PBS to remove excess primary antibody and cells were incubated in antirabbit FITC conjugated or anti-mouse Texas Red conjugated IgG (compatible with primary antibody) at a concentration of 1:500 for $1 \mathrm{~h}$ at room temperature. The slides were washed three times with PBS, mounted with 4', 6-diamidino-2phenylindole (DAPI) to visualize the nucleus, covered with glass cover slips, and fluorescent photomicrographs were obtained using a confocal microscope.

Spheroid migration assay. IOMM-Lee cells labeled with GFP (green fluorescence protein) were cultured at a concentration of $7 \times 10^{4}$ cells per well in $0.5 \%$ agarose-coated 96 -well plates and grown for $4-5$ days at $37^{\circ} \mathrm{C}$ with shaking at $40-60 \mathrm{rpm}$. The spheroids were transfected with $\mathrm{pSV}, \mathrm{pCB}, \mathrm{pM}$ and pMC. Untreated spheroids were also maintained under similar conditions to serve as the control (mock). Forty-eight hours following transfection, the spheroids were transferred to 8-well chamber slides, and grown in serum-free media for a further $72 \mathrm{~h}$. Migration of the cells from spheroids was recorded with a fluorescence microscope. Spheroid migration was quantified as the distance traveled by the tumor cells from the spheroids and values were plotted against the plasmid vectors used for transfection.

Matrigel invasion assay. Forty-eight hours following transfection of IOMM-Lee cells $\left(1 \times 10^{6}\right)$ with $\mathrm{pSV}, \mathrm{pCB}, \mathrm{pM}$ and pMC, cells were trypsinized and counted. Cells were also collected from untreated IOMM-Lee cell cultures that served as the control (mock). Cells $\left(1 \times 10^{5}\right)$ were counted using a hemocytometer, and were cultured in the upper chamber of a Transwell insert ( $8-\mu \mathrm{M}$ pores) coated with Matrigel $(1 \mathrm{mg} / \mathrm{ml})$ 
(Collaborative Research Inc., Boston, MA) in the presence of $500 \mu 1$ serum-free media. Serum-supplemented media (700 $\mu 1$ ) added to the lower chamber served as a chemoattractant and the chambers were maintained in an incubator at $37^{\circ} \mathrm{C}$. After a 48 -h incubation period, the chambers were removed from the incubator, non-migrated cells in the upper chamber were scraped off carefully, and migrated cells adhering to the lower surface of Transwell insert were stained with Hema-3. Photographs of the cells were taken at a magnification $\mathrm{x} 20$ with a light microscope. The cells were counted and quantification of invasion was performed using a previously established method (29).

Spheroid confrontation model. A 96-well plate coated with $0.5 \%$ agarose was used to culture $7 \times 10^{4}$ IOMM-Lee cells per well. The cells were grown in serum-supplemented $80 \mu 1$ DMEM media for 3-4 days with shaking at 40-60 rpm with periodic replacement of media. The spheroids selected were about 100-200 $\mu \mathrm{m}$ in diameter. The spheroids were transfected with pSV, pCB, pM, pMC, and after a 48-h incubation period, were labeled with the red fluorescent lipid dye Dil (1,1'-dioctadecyl-3, 3, 3', 3'-tetra methyl indocarbocyanine perchlorate; Molecular Probes; Invitrogen). Untreated spheroids were also maintained under similar conditions (mock). Sixteen- to 17-day-old fetal rat brain cells were cultured in 6-well plates and grown for 21 days at $37^{\circ} \mathrm{C}$ with shaking at $40-60 \mathrm{rpm}$. The fetal rat brain cell aggregates were labeled with green fluorescent lipid dye $\mathrm{DiO}$ (3,3'-dioctadecyloxacarbocyanine perchlorate; Molecular Probes; Invitrogen). Both of the fluorescent dyes used in the present study are reported to be non-toxic to cells and do not affect the invasive capacity of tumor cells. Following labeling with the fluorescent dyes, the tumor spheroids and brain cell aggregates were co-cultured in 96-well low attachment plates. The gradual invasion of fetal rat brain cell aggregates by tumor spheroids was recorded at 24,48 and $72 \mathrm{~h}$ using fluorescence microscopy. Image analysis software was used for quantification of invasion as the area of fetal rat brain cells remaining uninvaded by the tumor spheroids (28).

In vitro angiogenesis assay. IOMM-Lee cells were cultured in 8 -well chamber slides at a concentration $4 \times 10^{4}$ cells per well. The cells were transfected with $\mathrm{pSV}, \mathrm{pM}, \mathrm{pCB}$ and pMC and allowed to grow for $24 \mathrm{~h}$. Untreated cells were maintained to serve as the control (mock). Twenty-four hours after transfection, the serum-supplemented media was replaced with serum-free media and the cells were allowed to grow further for another $24 \mathrm{~h}$. The serum-free media from both untreated cells and transfected cells was collected (conditioned media). Simultaneously, $3 \times 10^{4}$ HMEC were grown for $24 \mathrm{~h}$ in 8 -well chamber slides. The conditioned media collected from the tumor cells were added to HMEC cells and the cells were further incubated at $37^{\circ} \mathrm{C}$. After $72 \mathrm{~h}$, conditioned media was removed and the cells were stained with $H \& E$. Pictures were taken with a light microscope and observed for capillary-like network formation. The percentage of capillary-like network formation was quantified as the product of the number of branch points formed by the HMEC cells after stimulation with conditioned media collected from the tumor cells and the number of branches originating from each branch (30).
Dorsal skin-fold chamber model. We used a previously established protocol (31) to detect in vivo angiogenesis in the presence of IOMM-Lee parental cells (mock) and cells treated with $\mathrm{pSV}, \mathrm{pCB}, \mathrm{pM}$ and $\mathrm{pMC}$. Diffusion chambers (Fisher Scientific, Pittsburgh, PA) were prepared by aligning $0.45 \mu \mathrm{m}$ Millipore membranes (Fisher) on both sides of the rim of the ' $\mathrm{O}$ ' ring (Fischer) with sealant prepared from a mixture of $250 \mathrm{mg}$ dental acrylic, $3 \mathrm{ml}$ dichloroethane, and $200 \mu 1$ 2-butanone. Chambers were dried and 2x10 IOMMLee cells suspended in sterile PBS were injected into the chambers through the opening provided in the chambers. The chambers were sealed with bone wax and placed in serum-free media to keep them wet until use. Animals were anesthetized as mentioned above and $5 \mathrm{ml}$ of air was injected to create a dorsal air sac. A $1.5-2 \mathrm{~cm}$ incision was made along the edge of the dorsal air sac. The chambers were carefully placed through the incision under the skin and incision was closed using sealing animal glue. The animals were sacrificed after 10 days. The skin around the implanted chambers was carefully removed and observed under a light microscope. Novel branches (irregularly arising branches, distinct from the regular organized blood vessels) were recorded as tumor-induced neovasculature.

\section{Establishment and treatment of orthotopic intracranial tumors} in athymic nude mice. Orthotopic tumors were established through intracranial injection of tumor cells into brains of athymic nude mice. Six animals were used for each group. IOMM-Lee cells were grown in serum-supplemented DMEM media for 2 days and trypsinized. The cells were counted and $0.5 \times 10^{6}$ cells were washed twice and suspended in sterile PBS. The cells were injected into anesthetized nude mice (50 mg/kg ketamine, $10 \mathrm{mg} / \mathrm{kg}$ xylazine) using a stereotactic frame (32).

The animals were maintained for one week to allow the tumors to develop and then divided into 5 treatment groups with 6 animals in each group. Alzet mini-osmotic pumps (Durect Corporation, CA) containing $150 \mu \mathrm{g}$ of plasmid at a concentration of $1.5 \mu \mathrm{g} / \mu 1$ were set up for each animal. The animals were treated with $\mathrm{pSV}, \mathrm{pCB}, \mathrm{pM}$ and $\mathrm{pMC}$ and allowed to grow for 3-4 weeks. Once the control group (i.e., mice that did not receive any treatment) showed chronic symptoms, the animals were euthanized by cardiac perfusion first using PBS followed by $10 \%$ phosphate-buffered formalin. The brains were removed and stored in $10 \%$ phosphatebuffered formalin and embedded in paraffin as per standard protocol. Sections were prepared and stained with H\&E. Serial sections of paraffin block were stained and volume of the tumor was taken as a product of tumor area and depth of tumor. Semi-quantitative analysis of the tumor sections was performed using image analysis software (30).

Immunofluorescence analysis of protein expression in tumor sections. Paraffin-embedded tumor sections were subjected to rehydration by passing through a series of xylene, $100 \%$ and $90 \%$ ethanol. The slides were washed in cold PBS and blocked for $30 \mathrm{~min}$ in 1\% BSA prepared in PBS followed by overnight incubation in primary antibody at a concentration of $1: 100$ at $4^{\circ} \mathrm{C}$. The slides were then washed three times with $1 \%$ BSA in PBS for 2 min per wash, and incubated for $1 \mathrm{~h}$ in appropriate fluorescence-labeled secondary antibody 


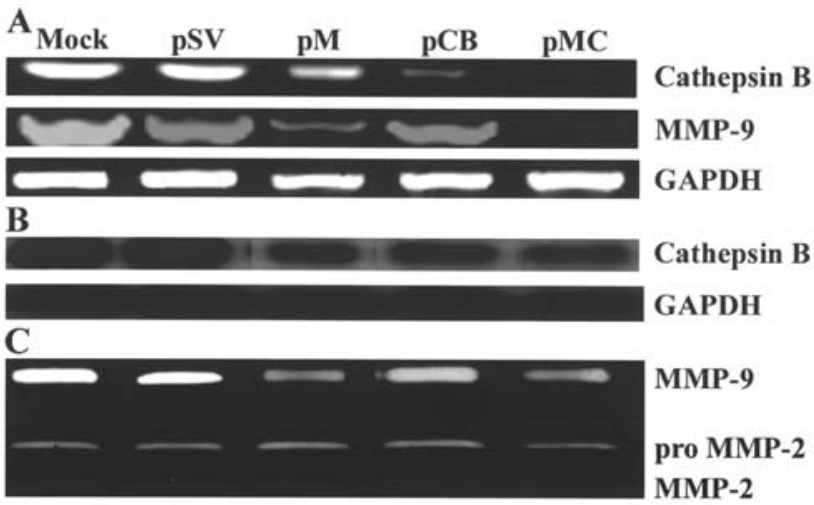

Figure 1. RNAi-mediated downregulation of cathepsin B and MMP-9 expression in IOMM-Lee cells. (A) Total RNA was extracted from IOMM-Lee parental cells (mock) and cells transfected with pSV, pCB, pM and pMC. Semi-quantitative RT-PCR was performed as per standard protocol. GAPDH expression was also analyzed in all the samples to serve as a loading control. (B) Cell lysates were collected from cells transfected with pSV, pCB, pM and $\mathrm{pMC}$ and also from parental cells (mock). Immunoblot analysis was performed using the cell lysates to detect expression of cathepsin B in the parental cells and the cells transfected with shRNA plasmids. GAPDH was analyzed as a loading control. (C) Enzymatic activity of MMP-9 was analyzed in the conditioned media collected from cells transfected with $\mathrm{pSV}, \mathrm{pCB}$, $\mathrm{pM}, \mathrm{pMC}$ and parental cells. Thirty $\mu \mathrm{g}$ of protein were loaded onto $10 \%$ SDS-PAGE containing gelatin.

(FITC-labeled secondary antibody for cathepsin B, Texas Red-labeled secondary antibody for MMP-9). The slides were kept in the dark to avoid exposure to light. Fields with intense fluorescence were scored for protein expression.

\section{Results}

Knockdown of cathepsin B and MMP-9 expression upon RNAi treatment. Fig. 1 shows decreased levels of cathepsin B and MMP-9 mRNA in $\mathrm{pCB}, \mathrm{pM}$ and $\mathrm{pMC}$ treated cells as compared to control and scrambled vector-treated samples. Immunoblot analysis of cell lysates was performed further to analyze whether protein expression also showed a similar trend in the treated IOMM-Lee cells. As shown in Fig. 1B there was a decrease in the expression of the cathepsin $B$ in pCB and pMC treated cells when compared to untreated cells or cells treated with $\mathrm{pSV}$. Treatment with pMC targeting both cathepsin B and MMP-9 showed a further decrease in protein expression when compared to the individual constructs GAPDH activity was analyzed at both mRNA and protein levels to serve as a loading control (results confirmed equal loading). Enzymatic activity of MMP-9 was analyzed in the conditioned media collected from the cells treated with $\mathrm{pSV}$, pCB, pM and pMC using gelatin zymography (Fig. 1C). A significant decrease of MMP-9 activity was observed in the cells treated with $\mathrm{pM}$ and $\mathrm{pMC}$ when compared to mock and pSV treated samples. Treatment with pCB did not result in a decrease in MMP-9 activity. However, treatment with pMC resulted in a more significant decrease in MMP-9 activity when compared to either mock, pSV-treated samples or samples treated with the single constructs ( $\mathrm{pCB}$ and $\mathrm{pM})$. There was no significant change in the levels of MMP-2 enzymatic activity with and without treated groups. Immunohistochemical analysis of protein expression of cathepsin B and MMP-9 was significantly decreased in $\mathrm{pCB}, \mathrm{pM}$ and pMC treated cells compared to controls and PSV treated cells (Fig. 2). Taken together, these results demonstrate the efficient downregulation of the cathepsin B and MMP-9 upon treatment with shRNA targeting these proteins.

Knockdown of cathepsin B and MMP-9 expression in IOMMLee cells upon siRNA treatment impedes cell proliferation. Earlier studies have reported a correlation between cathepsin B

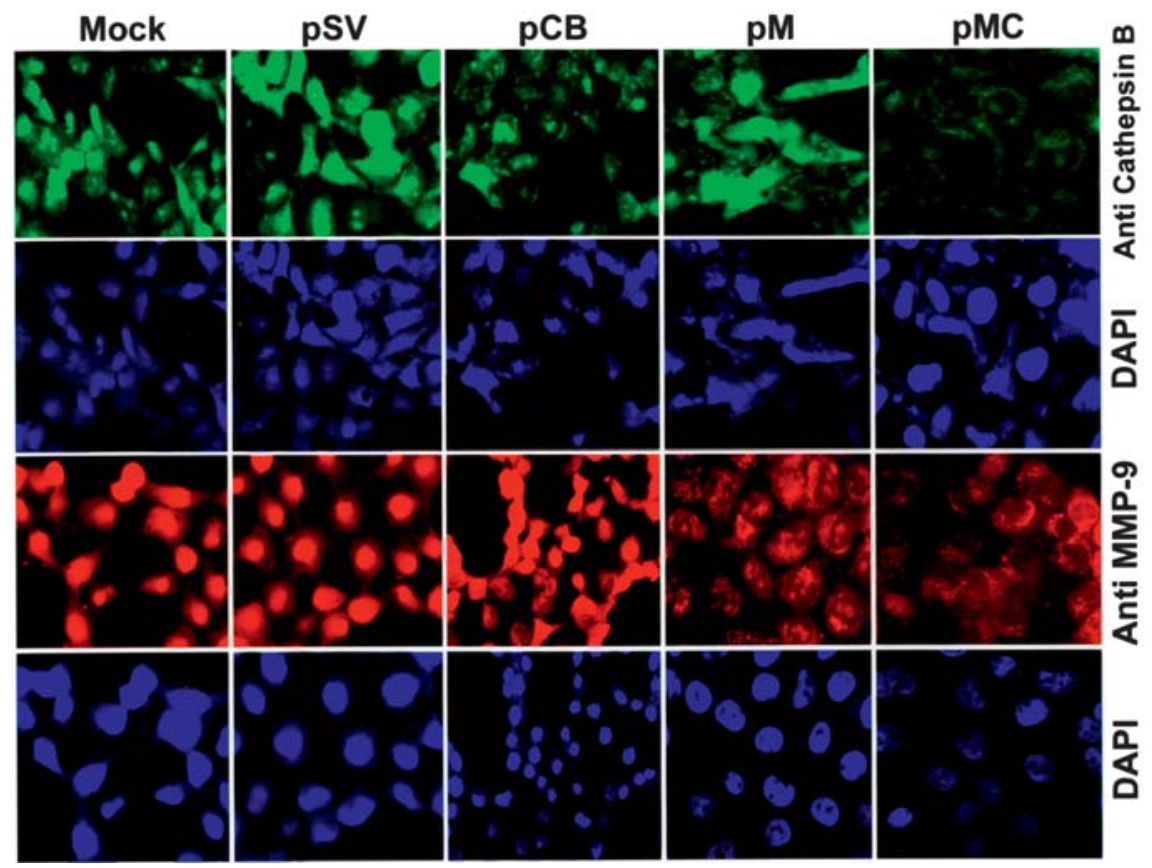

Figure 2. Detection of in situ cathepsin B and MMP-9 gene expression. IOMM-Lee cells were cultured in 8-well chamber slides at a concentration of 5x10 4 and transfected with pSV, pCB, pM and pMC. Parental cells (mock) were simultaneously maintained. Seventy-two hours after transfection, the cells were fixed in formaldehyde. Expression of cathepsin B and MMP-9 was detected in intact cells (see Materials and methods). The cells were mounted with 4',6-diamidino-2phenylindole (DAPI) to visualize the nucleus. 


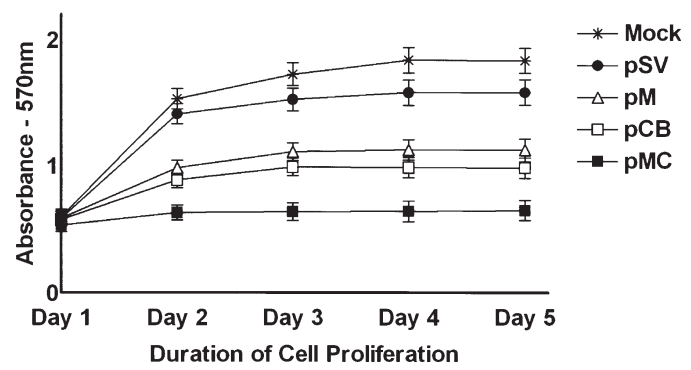

Figure 3. RNAi-mediated abrogation of cathepsin B and MMP-9 gene expression negates IOMM-Lee cell proliferation. IOMM-Lee cells $\left(5 \times 10^{3}\right)$ were maintained in triplicate in vitronectin-coated 96-well plates and transfected with $\mathrm{pSV}, \mathrm{pCB}, \mathrm{pM}$ and $\mathrm{pMC}$ as described in Materials and methods. Viable cell mass was measured in both parental and treated cells at different time intervals (1-5 days) $48 \mathrm{~h}$ after transfection. $\mathrm{A}_{570}$ was plotted against the respective time intervals. Mean \pm SD values from 3 different experiments are shown $(\mathrm{p}<0.001)$

A

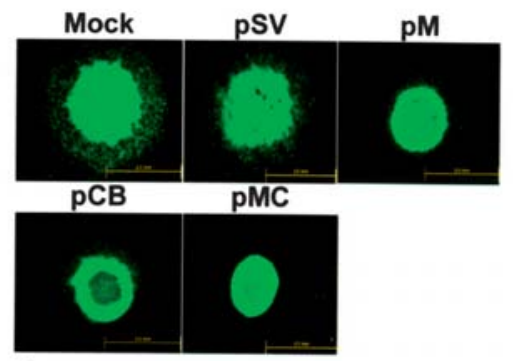

C

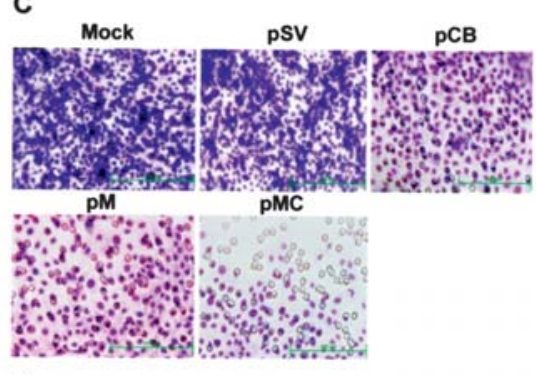

E

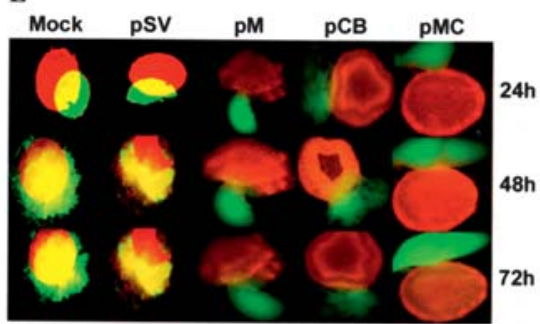

overexpression and an increase in cell proliferation during tumorigenesis (33). Following transfection with pSV, pCB, pM and $\mathrm{pMC}$, the cells were maintained in serum-supplemented media for 5 days. Fig. 3 shows that cell proliferation was decreased in cells transfected with $\mathrm{pCB}, \mathrm{pM}$ and $\mathrm{pMC}$ as compared to either parental cells (mock) or cells transfected with pSV. Furthermore, IOMM-Lee cells transfected with pMC showed the most significant decrease in cell proliferation when compared to cells transfected with either $\mathrm{pCB}$ or $\mathrm{pM}$ (Fig. 3).

RNAi-mediated downregulation of cathepsin B and MMP-9 reduces tumor cell migration and tumor invasion. In the present study, spheroids derived from IOMM-Lee cells and transfected with $\mathrm{pCB}, \mathrm{pM}$ and $\mathrm{pMC}$ showed decreased tumor cell migration when compared with spheroids derived from

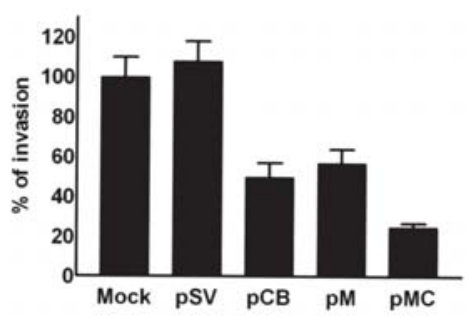

D
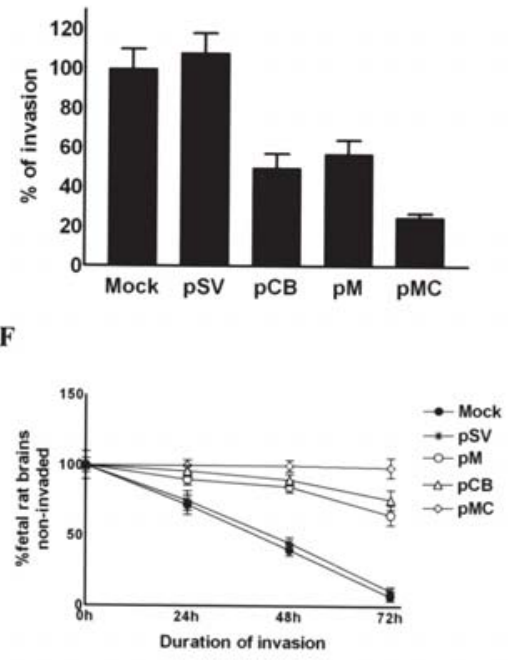

Figure 4. Knockdown of cathepsin B and MMP-9 through RNAi treatment reduces spheroid migration and invasion. (A) Fluorescent-labeled IOMM-Lee cells (IOMM-Lee GFP) were cultured in 96-well low attachment plates at a concentration of $7 \times 10^{4}$ and spheroids were allowed to grow for 3-4 days at $37^{\circ} \mathrm{C}$ with shaking at 40-60 rpm. The spheroids were then transfected with pSV, $\mathrm{pCB}, \mathrm{pM}$ and $\mathrm{pMC}$. Untreated spheroids were also maintained to serve as the control (mock). Forty-eight hours after transfection, the spheroids were transferred to 8 -well chamber slides and maintained for another $72 \mathrm{~h}$ in serum-free media. Spheroid migration was analyzed by taking pictures using fluorescence microscope. (B) The migration of the spheroid cells was quantified as the distance cells migrated from the spheroids. Values are mean \pm SD from three different experiments $(\mathrm{p}<0.001)$. (C) IOMM-Lee cells were transfected with $\mathrm{pSV}, \mathrm{pCB}, \mathrm{pM}$ and $\mathrm{pMC}$. Untransfected cells (mock) were also maintained to serve as the control. Forty-eight hours later, the cells were collected through trypsinization and resuspended in

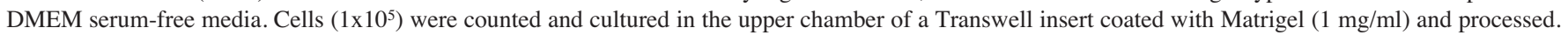
(D) Number of cells was counted in three different fields for each sample and the percentage invasion of cells treated with shRNA plasmids was analyzed and compared with the untreated (mock) cells. The graph represents the percentage invasion shown by cells transfected with $\mathrm{pSV}, \mathrm{pCB}, \mathrm{pM}$ and $\mathrm{pMC}$ in comparison with untreated cells (mock). Values are mean \pm SD from three different experiments $(p<0.001)$. (E) IOMM-Lee cells were cultured in agar-coated 96-well plates at a concentration of $7 \times 10^{4}$ and allowed to grow for 3-4 days in a $37^{\circ} \mathrm{C}$ incubator with shaking at $40-60 \mathrm{rpm}$. The spheroids were later transfected with pSV, $\mathrm{pCB}, \mathrm{pM}$ and pMC. Forty-eight hours after transfection, the cells were labeled with the red fluorescent dye Dil. Untreated spheroids (mock) were maintained as the control under similar conditions. Simultaneously, fetal rat brain aggregates (FRBA) were grown from 16-17-day-old fetal rat brain cells and labeled with the green fluorescent dye DiO. Later, both the IOMM-Lee spheroids and spheroids from fetal rat brain cells were co-cultured and maintained in serum-free media. Invasion of fetal rat brain spheroids by tumor cell spheroids was recorded at periodic intervals of 24,48 and $72 \mathrm{~h}$ using a fluorescent microscope. (F) The percentage of invasion in the untransfected spheroids and spheroids treated with shRNA plasmids was quantified using image analysis software and plotted as the fetal rat brain aggregates which remained uninvaded against different time intervals. Values shown are the mean $\pm \mathrm{SD}$ from three different experiments $(\mathrm{p}<0.001)$. 

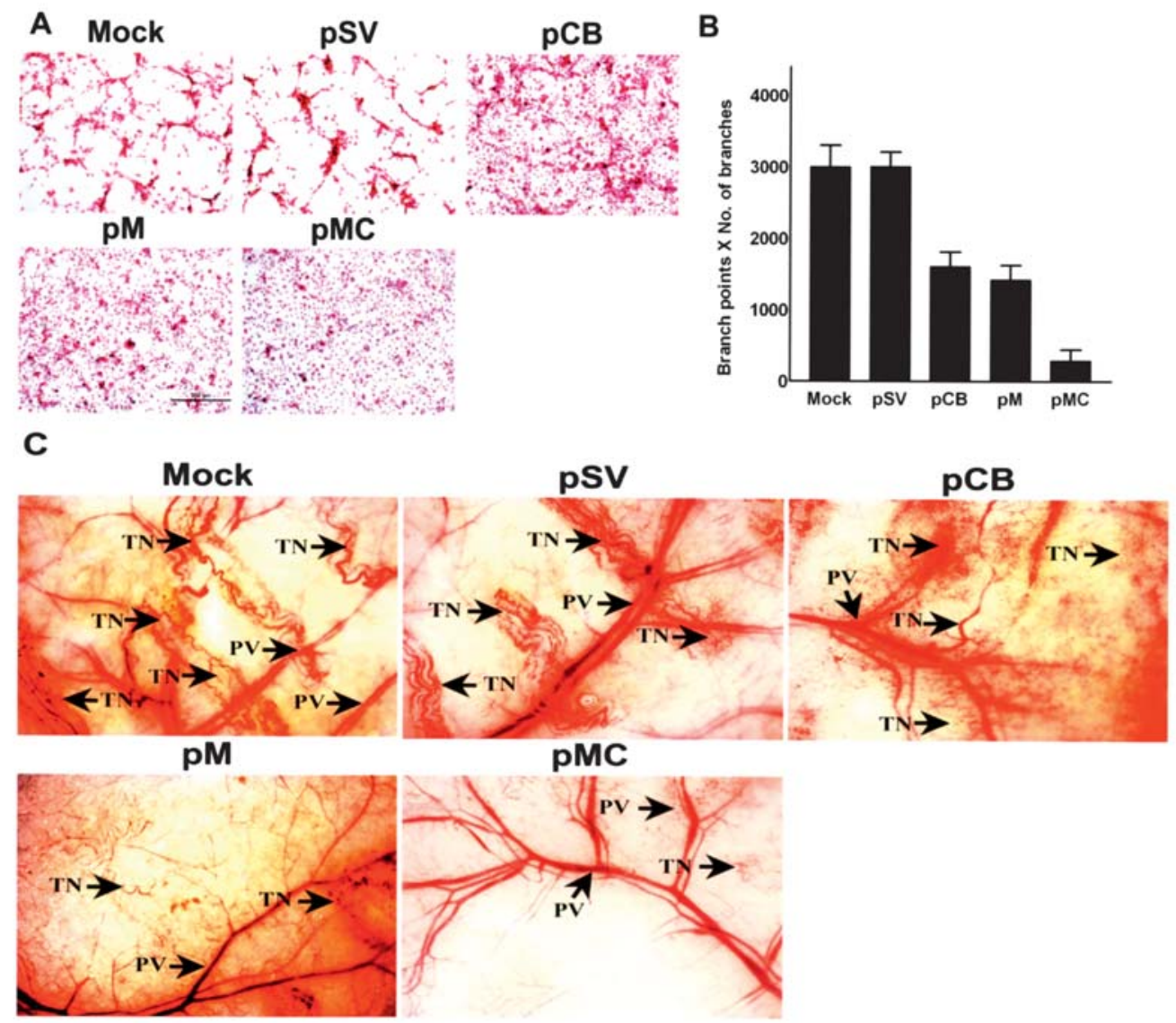

Figure 5. RNAi-mediated targeting of cathepsin B and MMP-9 inhibits angiogenesis initiated by IOMM-Lee cells. (A) IOMM-Lee cells (4x104) were cultured in 8 -well chamber slides and transfected with pSV, pCB, pM and pMC and grown for $24 \mathrm{~h}$. Untreated cells (mock) were maintained as a control. After $24 \mathrm{~h}$, the media was replaced with serum-free media and maintained for another $24 \mathrm{~h}$. Simultaneously, HMEC cells $\left(3 \times 10^{4}\right)$ were maintained in 8 -well chamber slides. The conditioned media was collected from transfected cells $24 \mathrm{~h}$ after adding serum-free media. HMEC were grown for another $72 \mathrm{~h}$ in the presence of conditioned media collected from parental (mock) and transfected IOMM-Lee cells. Then, HMEC were stained with H\&E and capillary-like network formation was analyzed under light microscopy. (B) The ability of capillary network formation was analyzed as number of branch points and number of branches per branch point and plotted against the respective cells. Values represent mean \pm SD from three different experiments ( $<<0.001)$. (C) The dorsal skin fold chamber model results revealed inhibition of in vivo angiogenesis, most likely due to RNAi-mediated abrogation of cathepsin B and MMP-9. Diffusion chambers holding 2x10 6 IOMM-Lee parental cells and cells transfected with pSV, pCB, pM and pMC were introduced into dorsal air sacs of athymic nude mice as described in Materials and methods. Ten days after introduction of the diffusion chambers, the animals were sacrificed. The skin around the chamber was carefully removed and observed under a light microscope. Delicate, zigzag-shaped microvessels with irregular arrangement was recorded as tumor-induced neovasculature $(\mathrm{TN})$ and were compared to the more organized pre-existing vasculature (PV).

untreated cells and cells transfected with pSV (Fig. 4A). Again, we observed the most significant decrease in the migration of spheroids treated with $\mathrm{pMC}$ as compared to spheroids transfected with either $\mathrm{pCB}$ or $\mathrm{pM}$, thereby indicating a cumulative effect of the downregulation of cathepsin $\mathrm{B}$ and MMP-9 (Fig. 4A and B).

There was a significant decrease in the invasive ability of cells treated with $\mathrm{pCB}, \mathrm{pM}$ and $\mathrm{pMC}$ when compared to parental cells (mock) or cells treated with pSV. The most significant decrease in invasive ability was observed in cells treated with pMC as compared to either pCB- or pM-treated cells (Fig. 4C and D). Spheroids derived from parental IOMM-Lee cells and also cells transfected with pSV, pCB, $\mathrm{pM}$ and $\mathrm{pMC}$ were co-cultured with fetal rat brain aggregates. Tumor spheroids derived from the parental cells (mock) and spheroids transfected with pSV attached efficiently and invaded fetal rat brain aggregates, whereas spheroids transfected with $\mathrm{pCB}, \mathrm{pM}$ and $\mathrm{pMC}$ showed diminished attachment and invasion. Moreover, spheroids transfected with pMC showed further decrease in attachment and invasion of fetal rat brain aggregates when compared to spheroids transfected with either of the single constructs (Fig. 4E and F).

Downregulation of cathepsin B and MMP-9 through RNA interference inhibits angiogenesis. It is well known that several proteolytic cascades play important roles in angiogenesis during tumor progression. Numerous studies have documented that MMP-9 aids angiogenesis through extracellular matrix degradation and release of growth factors (34). Similarly, a positive correlation between the expression of cathepsin B and angiogenesis has been reported (35). Based on these studies, we decided to determine the effect of RNAi-mediated downregulation of these enzymes on angiogenesis in vitro. Well-defined capillary network formation was observed in parental cells and cells transfected with pSV, whereas cells transfected with $\mathrm{pCB}$ and $\mathrm{pM}$ showed significant decreases in network formation. Furthermore, the most significant decrease in capillary-like network formation was observed in cells transfected with pMC as compared to cells transfected with either pCB or pM (Fig. 5A and B). 
Further to confirm the in vitro co-culture experiments, we examined whether the pMC vector can inhibit tumor angiogenesis in vivo as assessed by the dorsal skin fold chamber model. In the mice that received dorsal chambers with parental IOMM-Lee cells or pSV-transfected cells, we observed a clear dense network of thin microvessels. Tumorinduced neovasculature is characterized by a zigzag shape and an irregular arrangement as compared to the more organized, pre-existing vasculature. Tiny bleeding spots were also observed, which indicate incomplete angiogenesis. However, in the mice that received IOMM-Lee cells transfected with $\mathrm{pCB}, \mathrm{pM}$ and $\mathrm{pMC}$, microvessel formation was considerably less than in mice that received parental cells or pSV (Fig. 5C). When compared, pCB-transfected cells and pM-transfected cells showed less microvessel formation, probably owing to the potent role played by MMP-9 in angiogenesis. Furthermore, pMC-transfected cells showed the most significant decrease in microvessel formation when compared to either pCB- or pM-transfected cells (Fig. 5C).

Targeting cathepsin B and MMP-9 through RNAi treatment interferes with downstream signaling events. In eukaryotic cells, intracellular signaling cascades serve as the main communication between the plasma membrane and various compartments of cells, and are actively involved in the cellular response to external stimuli. These cascades are often exploited during tumorigenesis in favor of tumor growth. Involvement of the MAPK and PI3 kinase pathways in signal transduction and their modulation to promote tumor growth are well documented. As such, we analyzed the effect of the RNAi-mediated downregulation of cathepsin B and MMP-9 on these intracellular signaling pathways. Fig. 6 shows that no significant decrease in the expression of total ERK, Jnk, p38 and phosphorylation of Jnk and p38, but we did observe significant decreases in the phosphorylation of ERK1 (p42) and ERKII (p44) in the cells treated with pCB, $\mathrm{pM}$ and $\mathrm{pMC}$ when compared to either parental or pSVtransfected cells. Notably, the bicistronic construct pMC effected the most significant decrease in the phosphorylation of these MAP kinases compared to cells treated with single constructs (Fig. 6). The PI3 kinase pathway is also actively involved in cell survival (36). In the present study, we did not observe a decrease in total PI3 kinase and Akt-the two main components of this pathway. However, phosphorylation of Akt decreased significantly in the cells treated with pCB, $\mathrm{pM}$ and pMC when compared to the parental cells or cells treated with pSV (Fig. 6). Our results substantiate that RNAimediated downregulation of cathepsin B and MMP-9 led to reduction of tumor cell migration, invasion and angiogenesis in vitro. Based on these observations, we next determined the therapeutic efficacy of RNAi-mediated downregulation of these proteins in orthotopic tumors established in nude mice.

Downregulation of cathepsin B and MMP-9 leads to regression of pre-established orthotopic tumors in nude mice. As described previously (31), 0.5 × $10^{6}$ IOMM-Lee meningioma cells were administered intracranially to athymic nude mice using a stereotactic frame. The animals were maintained for one week to allow the tumors to grow further, followed by treatment with various plasmid constructs as described

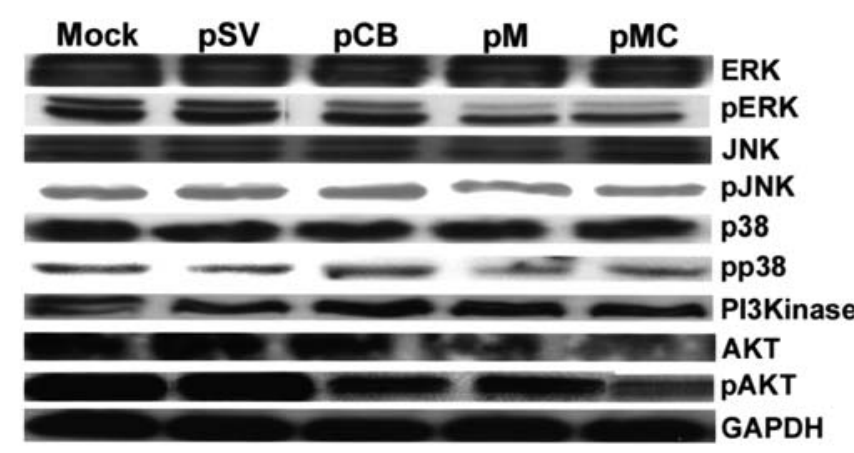

Figure 6. RNAi-mediated downregulation of cathepsin B and MMP-9 gene expression effects intracellular signaling events. IOMM-Lee cells were transfected with $\mathrm{pSV}, \mathrm{pCB}, \mathrm{pM}$ and $\mathrm{pMC}$; untreated cells (mock) were maintained to serve as the control. The cells were lysed after $48 \mathrm{~h}$ and cell lysates were analyzed for various proteins participating in the MAPK and PI3 kinase intracellular signaling pathway molecules by Western blotting as described in Materials and methods.

above. Sections of about 4-8 microns were taken for further investigation. $\mathrm{H} \& \mathrm{E}$ staining of the sections revealed prolific tumor growth in both untreated and animals treated with $\mathrm{pSV}$ (Fig. 7A). However, sections from the brains of treated animals revealed significant regression of the tumors. Sections from animals treated with pMC showed an almost complete tumor regression (Fig. 7A and B). Further, immunofluorescence analysis of cathepsin B and MMP-9 expression in the tumor sections revealed decreased expression of these proteins in the brains of animals that received RNAi treatment when compared to the controls (Fig. 7C).

\section{Discussion}

Tumor progression is a multifaceted process, which is initiated through activation and/or modulation of various proteolytic systems. These proteolytic cascades, once modified, assist several aspects of tumorigenesis. Irrespective of histological type of origin, invasion is one of the inherent properties acquired by transformed brain cells. During invasion, the tumor cells detach from the primary tumor mass and reattach to the extracellular matrix or surrounding tissue. This process involves excessive secretion of several proteases, which degrade the extracellular matrix (ECM), thereby creating momentary access for the tumor cells to invade into surrounding tissue. Previous studies performed by our group have established cathepsin B and MMP-9 as potential targets for therapeutic treatment of glioblastoma. We found that downregulation of these proteinases through antisense or RNAi-mediated approach reduced tumor growth, invasion and angiogenesis $(28,37)$. Meningiomas are the most commonly occurring brain tumors, but very little is known about the underlying molecular mechanism. Moreover, depending on their position in the brain, meningiomas can pose difficulty during surgical resection. At present, apart from surgical resection of the tumor, radiation therapy is generally used for treatment of meningiomas and other alternative treatments are under trial. In recent years, the RNAi-mediated approach has emerged as a promising schema for the treatment of various in vivo disease models (38). Our investigation uses 
A

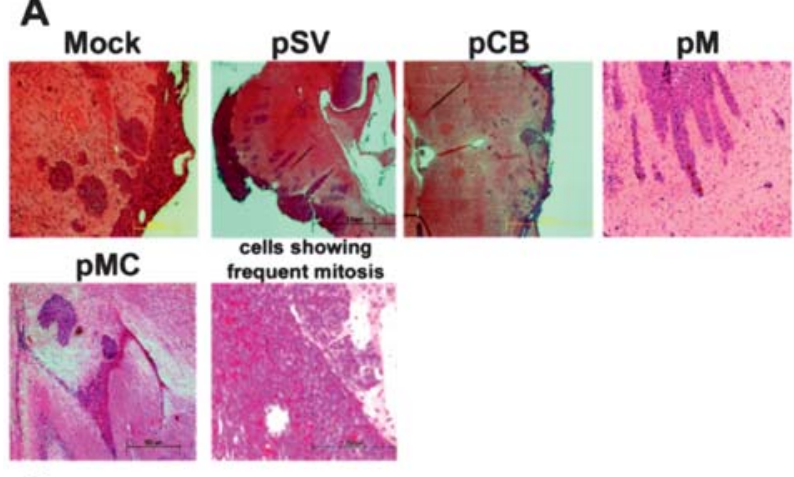

B

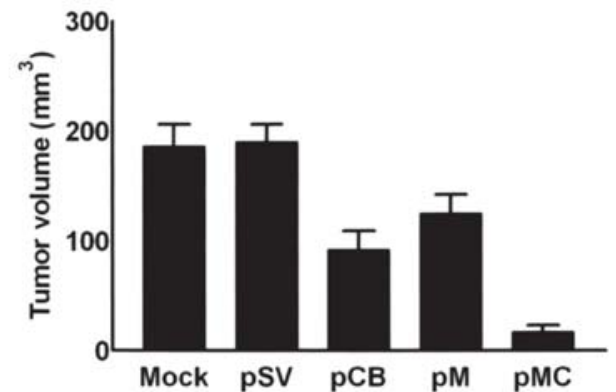

C

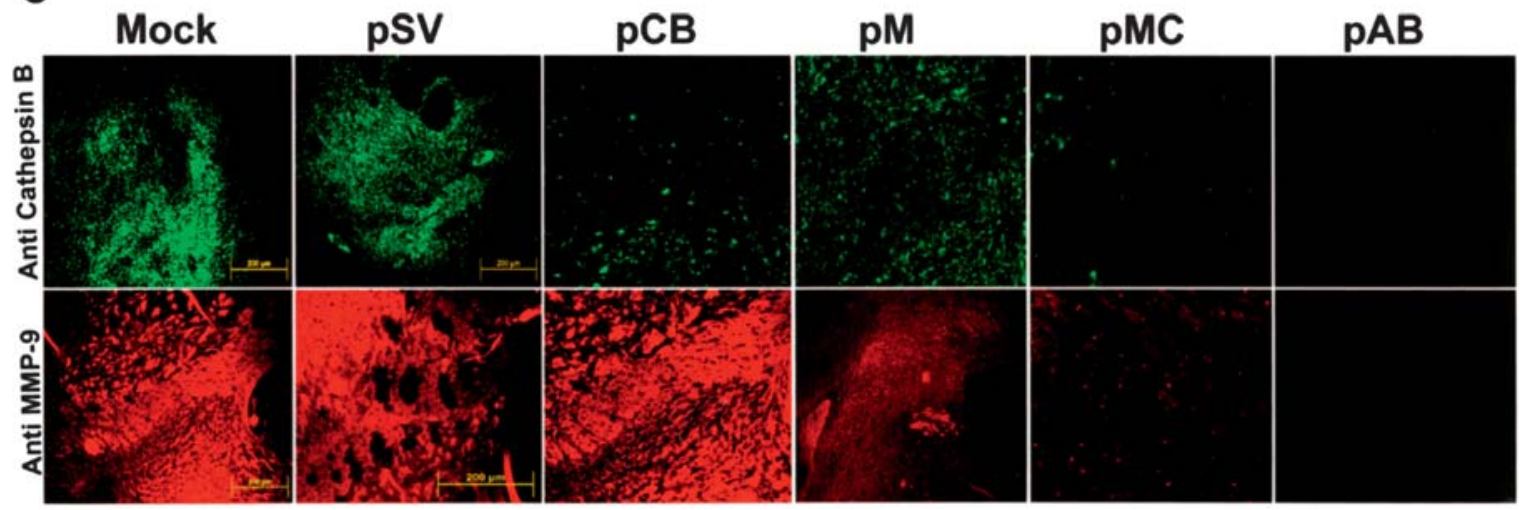

Figure 7. Downregulation of cathepsin B and MMP-9 through RNAi treatment leads to regression of pre-established orthotopic tumors. (A) Orthotopic intracranial tumors were established in nude mice and treated with shRNA plasmids. Following extraction, the brains were paraffin-embedded, sectioned and stained with H\&E. Photomicrographs of tumor sections revealing total tumor (x40) and rapidly dividing tumor cells (x4000) are shown in the figure. (B) Semiquantification of tumor volume was performed as described in Materials and methods. Values represent mean \pm SD from five different animals. (C) Immunofluorescence detection of cathepsin B and MMP-9 expression in tumor sections. Paraffin-embedded tumor sections were subjected to immunofluorescence detection of cathepsin B and MMP-9 expression. Following incubation in appropriate secondary antibody, slides were mounted and observed under a fluorescent microscope. Fields with intense fluorescence were scored for protein expression.

this approach to examine the therapeutic significance of RNAi-mediated downregulation of cathepsin B and MMP-9 in malignant meningiomas.

Overexpression of cathepsin B by the tumor cells and adjacent stromal cells have been reported in human breast carcinoma and fibroadenoma (39). Recent studies in highly invasive melanoma cells reported an increased release of mature cathepsin B upon contact of the cells with collagen I and affirmed an active role of cathepsin B in extracellular matrix degradation $(40,41)$. Augmentation of both cathepsin B and MMP-9 expression and their cumulative role in attributing aggressiveness to budding tumors has been reported in colorectal cancer (4). Several earlier studies on various cancers have revealed that matrix metalloproteinases act in concert with serine and cysteine proteinases resulting in tissue remodeling and ECM degradation, which in turn, enable tumor growth, invasion and angiogenesis (42). Enhanced expression of both MMP-2 and MMP-9 was reported in human colorectal cancer (43). In the present study, administration of shRNA plasmids into IOMM-Lee cells targeting cathepsin B and MMP-9 efficiently downregulated expression of these proteins, both at the mRNA and protein levels, when compared to the parental cells by western blotting, gelatin zymography and immunohistochemical analysis.

Aggressive proliferation of cells is a characteristic feature of malignant tumors irrespective of source of origin. Once transformed, tumor cells divide aggressively and thus, aid in the propagation of the tumor. Several proteolytic systems, apart from proteolysis also send mitogenic signals to cellular machinery. Enhanced expression of cathepsin B and active participation in tumor progression was reported in lung cancer (44). Elevated MMP-9 expression has also been observed in several cancer scenarios where there is increased cell proliferation (45). Because cell proliferation is an essential feature of tumor progression, we evaluated the proliferative ability of IOMM-Lee cells following downregulation of cathepsin B and MMP-9 through RNA interference. Downregulation of cathepsin B and MMP-9 hampered cell proliferation significantly in the IOMM-Lee cells transfected with $\mathrm{pCB}, \mathrm{pM}$ and $\mathrm{pMC}$ when compared to either untreated cells (mock) or cells transfected with pSV. The ability to invade surrounding tissue is a hallmark of malignant tumors and this characteristic allows the tumor to establish and propagate in an altered environment. Migration of tumor cells not only helps the tumor to establish in the primary site, but is also required for metastasis to secondary sites. In the present study, the migratory capacity of tumor cells was evaluated following knockdown of cathepsin B and MMP-9. Interestingly, knockdown of cathepsin B and MMP-9 reduced migration of tumor spheroids significantly when compared to parental and $\mathrm{pSV}$-treated spheroids.

Several previous studies have established the roles played by both cathepsin B and MMP-9 during tumor invasion and metastasis. Elevated secretion of both precursor and active 
forms of cathepsin B followed by altered trafficking in the cell (i.e., the redistribution from perinuclear lysosomes to peripheral vesicles and association with plasma membrane) has been reported to occur in several forms of cancer (46-48). Intracellular and extracellular cathepsin B activity contributes to the in vitro invasiveness of MCF 10AT cells (49). Synthetic cysteine proteinase inhibitors, selective for cathepsin B, have been shown to significantly reduce the invasiveness of MCF $10 A T$ cells (50). There was a reduction in the number of lung colonies formed in an experimental metastasis in MMP-9 null mice (51) as well as inhibition of MMP-9 expression (52). MMP-9 has been shown to actively degrade triple helix type IV collagen of basal lamina of basement membrane and thus aid in tumor invasion (53). Studies on cell adhesion, migration and invasion of the prostate cancer cell line LNCap revealed that high expression levels of MMP-2 and MMP-9 correlate with increased tumor migration and invasion (54). Our results also demonstrated that the invasive potential of meningioma cells treated with the pMC vector was significantly inhibited. Together, these studies establish the significance of MMP-9 and cathepsin B on tumor invasion.

Angiogenesis is an important aspect of tumor progression and metastasis. At present, several studies are currently underway to find methods to effectively prevent angiogenesis, which would result in a better prognosis for several cancers. A recent study in human melanoma cells revealed that acidic extracellular $\mathrm{pH}$ existing in the tumor microenvironment stimulates overexpression of various pro-angiogenic factors including cathepsin B and MMP-9 and thus promotes pulmonary metastasis and angiogenesis (24). Cathepsins B and $\mathrm{L}$ are highly expressed in pancreatic islet cell carcinogenesis. In these cells, mutations in the cathepsin B gene aimed to inactivate the protein impaired tumor growth and angiogenesis (33). In another recent study, Olsson et al (55) reported a strong association between MMP-9 and angiogenesis through stimulation of VEGF. Tumor-associated macrophages are reported to release pro-angiogenic factors such as MMP-9 and VEGF. Blocking the release of these factors from macrophages resulted in the suppression of angiogenesis (56). In this study, we noted a reduction in capillary-like network formation of both in vitro and in vivo models of HMEC (human endothelial cells) when IOMM-Lee cells transfected with pCB, pM and pMC compared to controls and pSV-treated cells.

It is well known that normal cells, upon transformation to malignant cells, modulate several intracellular signaling pathways in order to establish themselves in an altered environment. This modulation is essential because extracellular signals interface with various intracellular regulatory targets through these signaling cascades, which generally involve a sequential activation of protein kinases through phosphorylation. Having observed a reduction in various aspects of tumorigenesis such as migration, invasion and angiogenesis, we next studied the effect of the downregulation of these proteins on intracellular signaling pathways. Stable transfection of pTEN reduced MMP-9 secretion caused by hyaluronic acid-induced phosphorylation of focal adhesion kinase and ERK1/ERK2 signaling (57). Both signal transduction pathways, MAPK/ERK and PI3-K pathways, are responsible for mediating increased MMP-9 levels following EGFR activation and appear to promote the association of pro-MMP-9 with the cell surface
(58). Inhibition of ERK specific inhibitors blocked MMP-9 expression in breast cancer cells (59). Moreover, prolonged activation of ERK signaling is necessary to induce MMP-9 activity (60). Our results demonstrated that mt-ERK transfected cells showed decreased levels of MMP-9 activity and are also less invasive in Matrigel invasion assay (61). It has been reported that hepatitis B viral HBx induces the MMP-9 gene expression through activation of ERKs (62). It has been recently reported that, inhibition of cathepsin B prevents the appearance of multi-nucleated cells, an early characteristic of MSA-induced cell death, pointing to a central, proximal role for cathepsin B in the novel death pathway (63). Several studies indicated that PI3-K and AKT pathways induce proliferation of glioma cell lines (64). Several earlier studies established the significant roles of ERK1 and ERK 2 in cell proliferation (65). In the present study, downregulation of cathepsin B and MMP-9 decreased phosphorylation of MAP kinases, ERK1, ERK2, PI3-K, and AKT levels.

As already stated, RNA interference has emerged as an extremely potent technology for the explicit downregulation of selected target genes. In recent years, scientists have upgraded the use of this technology from in vitro culture studies to in vivo administration in mammals. Based on the reductions that we observed in various aspects of tumor progression in the present study, we analysed the in vivo efficacy of downregulation of cathepsin B and MMP-9 in regressing pre-established orthotopic tumors in nude mice. Whereas parental and scrambled vector (pSV)-treated mice presented with enormous tumors, we observed significant tumor regression in the mice that received $\mathrm{pCB}, \mathrm{pM}$ and pMC. RNAi technology uses an intricate natural pathway for sequence-specific mRNA degradation and regulates gene expression at the post-transcriptional level. Delivery of small RNA is accomplished through several methods. While synthetic RNA duplexes are introduced into biological systems directly, the RNAi effect is only transient. However, recent studies indicate that introducing DNA-directed RNAi expression cassettes through plasmid or viral vectors serve as an excellent source of RNAi supply to the biological system under investigation. In this case, dsRNA is continuously expressed within the cells using the DNA templates that direct synthesis of RNA duplexes or short hairpin RNAs, and thus, depending on the vector employed, RNAi effect can be sustained long term. The size of the siRNA molecules ( $25 \mathrm{bp}$ ) is small enough to be transmitted from cell to cell, which has been reported previously (66). Several earlier studies have revealed that both the proteinases in the present study - cathepsin B and MMP-9 - play affirmative roles in various aspects of tumorigenesis in different types of cancer. However, at present, details on the role of these proteinases in malignant meningioma are not available. Consequently, the role of both these proteins in meningiomas merits further investigation. Our study clearly demonstrates that the downregulation of cathepsin B and MMP-9 in the malignant meningioma cell line IOMM-Lee resulted in the reduction of various aspects of tumorigenesis such as invasion, angiogenesis and migration. Our in vivo studies also revealed significant tumor regression, indicating that these proteinases might serve as potential candidates for therapeutic targets for the treatment of malignant meningioma. 


\section{Acknowledgements}

The authors thank Shellee Abraham for preparing the manuscript and Diana Meister and Sushma Jasti for manuscript review. We also thank Noorjehan Ali for technical assistance. This research was supported by National Cancer Institute Grant CA 75557, CA 92393, CA 95058, CA 116708, N.I.N.D.S. NS47699 and NS057529, and Caterpillar, Inc., OSF Saint Francis, Inc., Peoria, IL (to J.S.R.).

\section{References}

1. Erman T, Hanta I, Haciyakupoglu S, Zorludemir S, Zeren H and Gocer AI: Huge bilateral pulmonary and pleural metastasis from intracranial meningioma: a case report and review of the literature. J Neurooncol 74: 179-181, 2005.

2. Clarke MR, Weyant RJ, Watson CG and Carty SE: Prognostic markers in pheochromocytoma. Hum Pathol 29: 522-526, 1998.

3. DiCarlo A, Terracciano D, Mariano A and Macchia V: Urinary gelatinase activities (matrix metalloproteinases 2 and 9) in human bladder tumors. Oncol Rep 15: 1321-1326, 2006.

4. Guzinska-Ustymowicz K: MMP-9 and cathepsin B expression in tumor budding as an indicator of a more aggressive phenotype of colorectal cancer (CRC). Anticancer Res 26: 1589-1594, 2006.

5. Naka T, Boltze C, Kuester D, Schulz TO, Samii A, Herold C, Ostertag $\mathrm{H}$ and Roessner A: Expression of matrix metalloproteinase (MMP)-1, MMP-2, MMP-9, cathepsin B and urokinase plasminogen activator in non-skull base chordoma. Am J Clin Pathol 122: 926-930, 2004.

6. Roshy S, Sloane BF and Moin K: Pericellular cathepsin B and malignant progression. Cancer Metastasis Rev 22: 271-286, 2003.

7. Creemers LB, Hoeben KA, Jansen DC, Buttle DJ, Beertsen W and Everts V: Participation of intracellular cysteine proteinases, in particular cathepsin $\mathrm{B}$, in degradation of collagen in periosteal tissue explants. Matrix Biol 16: 575-584, 1998.

8. Kobayashi H, Moniwa N, Sugimura M, Shinohara H, Ohi H and Terao T: Effects of membrane-associated cathepsin B on the activation of receptor-bound prourokinase and subsequent invasion of reconstituted basement membranes. Biochim Biophys Acta 1178: 55-62, 1993.

9. Sinha AA, Gleason DF, Deleon OF, Wilson MJ and Sloane BF: Localization of a biotinylated cathepsin B oligonucleotide probe in human prostate including invasive cells and invasive edges by in situ hybridization. Anat Rec 235: 233-240, 1993.

10. Murnane MJ, Sheahan K, Ozdemirli M and Shuja S: Stagespecific increases in cathepsin B messenger RNA content in human colorectal carcinoma. Cancer Res 51: 1137-1142, 1991.

11. Rempel SA, Rosenblum ML, Mikkelsen T, Yan PS, Ellis KD, Golembieski WA, Sameni M, Rozhin J, Ziegler G and Sloane BF: Cathepsin B expression and localization in glioma progression and invasion. Cancer Res 54: 6027-6031, 1994.

12. Sivaparvathi M, Sawaya R, Wang SW, Rayford A, Yamamoto M, Liotta LA, Nicolson GL and Rao JS: Overexpression and localization of cathepsin B during the progression of human gliomas. Clin Exp Metastasis 13: 49-56, 1995.

13. Frohlich E, Schlagenhauff B, Mohrle M, Weber E, Klessen C and Rassner G: Activity, expression and transcription rate of the cathepsins $\mathrm{B}, \mathrm{D}, \mathrm{H}$ and $\mathrm{L}$ in cutaneous malignant melanoma. Cancer 91: 972-982, 2001

14. Hughes SJ, Glover TW, Zhu XX, Kuick R, Thoraval D, Orringer MB, Beer DG and Hanash S: A novel amplicon at 8p22-23 results in overexpression of cathepsin B in esophageal adenocarcinoma. Proc Natl Acad Sci USA 95: 12410-12415, 1998 .

15. Kusunoki T, Nishida S, Nakano T, Funasaka K, Kimoto S, Murata K and Tomura T: Study on cathepsin B activity in human thyroid tumors. Auris Nasus Larynx 22: 43-48, 1995.

16. Krueger S, Kalinski T, Wolf H, Kellner U and Roessner A: Interactions between human colon carcinoma cells, fibroblasts and monocytic cells in coculture-regulation of cathepsin B expression and invasiveness. Cancer Lett 223: 313-322, 2005.

17. Liu JP, Liu NS, Yuan HY, Guo Q, Lu H and Li YY: Human homologue of seta binding protein 1 interacts with cathepsin B and participates in TNF-induced apoptosis in ovarian cancer cells. Mol Cell Biochem (In press).
18. Silletti S, Yebra M, Perez B, Cirulli V, McMahon M and Montgomery AM: Extracellular signal-regulated kinase (ERK)dependent gene expression contributes to L1 cell adhesion molecule-dependent motility and invasion. J Biol Chem 279: 28880-28888, 2004

19. Arkona C and Wiederanders B: Expression, subcellular distribution and plasma membrane binding of cathepsin B and gelatinases in bone metastatic tissue. Biol Chem 377: 695-702, 1996.

20. Nikkola J, Vihinen P, Vuoristo MS, Kellokumpu-Lehtinen P, Kahari VM and Pyrhonen S: High serum levels of matrix metalloproteinase-9 and matrix metalloproteinase-1 are associated with rapid progression in patients with metastatic melanoma. Clin Cancer Res 11: 5158-5166, 2005.

21. Turpeenniemi-Hujanen T: Gelatinases (MMP-2 and -9) and their natural inhibitors as prognostic indicators in solid cancers. Biochimie 87: 287-297, 2005.

22. Cho NH, Shim HS, Rha SY, Kang SH, Hong SH, Choi YD, Hong SJ and Cho SH: Increased expression of matrix metalloproteinase 9 correlates with poor prognostic variables in renal cell carcinoma. Eur Urol 44: 560-566, 2003.

23. Van Hinsbergh VW, Engelse MA and Quax PH: Pericellular proteases in angiogenesis and vasculogenesis. Arterioscler Thromb Vasc Biol 26: 716-728, 2006.

24. Rofstad EK, Mathiesen B, Kindem K and Galappathi K: Acidic extracellular $\mathrm{pH}$ promotes experimental metastasis of human melanoma cells in athymic nude mice. Cancer Res 66: 6699-6707, 2006.

25. Frlan R and Gobec S: Inhibitors of cathepsin B. Curr Med Chem 13: 2309-2327, 2006.

26. Zwicky R, Muntener K, Goldring MB and Baici A: Cathepsin B expression and down-regulation by gene silencing and antisense DNA in human chondrocytes. Biochem J 367: 209-217, 2002.

27. Kettner-Buhrow D, ttrich-Breiholz O, Schneider H, Wolter S, Resch K and Kracht M: Small interfering RNAs generated by recombinant dicer induce inflammatory gene expression independent from the TAK1-NFkappaB-MAPK signaling pathways. Biochem Biophys Res Commun 347: 566-573, 2006.

28. Lakka SS, Gondi CS, Yanamandra N, Olivero WC, Dinh DH, Gujrati M and Rao JS: Inhibition of cathepsin B and MMP-9 gene expression in glioblastoma cell line via RNA interference reduces tumor cell invasion, tumor growth and angiogenesis. Oncogene 23: 4681-4689, 2004.

29. Mohanam S, Jasti SL, Kondraganti SR, Chandrasekar N, Lakka SS, Kin Y, Fuller GN, Yung AW, Kyritsis AP, Dinh DH, Olivero WC, Gujrati M, Ali-Osman F and Rao JS: Downregulation of cathepsin $\mathrm{B}$ expression impairs the invasive and tumorigenic potential of human glioblastoma cells. Oncogene 20: 3665-3673, 2001

30. Gondi CS, Lakka SS, Dinh D, Olivero W, Gujrati M and Rao JS: Downregulation of uPA, UPAR and MMP-9 using small, interfering, hairpin RNA (siRNA) inhibits glioma cell invasion, angiogenesis and tumor growth. Neuron Glia Biol 1: 165-176, 2004.

31. Leunig M, Yuan F, Menger MD, Boucher Y, Goetz AE, Messmer K and Jain RK: Angiogenesis, microvascular architecture, microhemodynamics and interstitial fluid pressure during early growth of human adenocarcinoma LS174T in SCID mice. Cancer Res 52: 6553-6560, 1992.

32. Brockmann MA, Westphal M and Lamszus K: Improved method for the intracerebral engraftment of tumour cells and intratumoural treatment using a guide screw system in mice. Acta Neurochir (Wien) 145: 777-781, 2003.

33. Gocheva V, Zeng W, Ke D, Klimstra D, Reinheckel T, Peters C, Hanahan D and Joyce JA: Distinct roles for cysteine cathepsin genes in multistage tumorigenesis. Genes Dev 20: 543-556, 2006.

34. Li T, Li YG and Pu DM: Matrix metalloproteinase-2 and -9 expression correlated with angiogenesis in human adenomyosis. Gynecol Obstet Invest 62: 229-235, 2006.

35. Kruszewski WJ, Rzepko R, Wojtacki J, Skokowski J, Kopacz A, Jaskiewicz K and Drucis K: Overexpression of cathepsin B correlates with angiogenesis in colon adenocarcinoma. Neoplasma 51: 38-43, 2004

36. Wilkins A, Majed H, Layfield R, Compston A and Chandran S: Oligodendrocytes promote neuronal survival and axonal length by distinct intracellular mechanisms: a novel role for oligodendrocyte-derived glial cell line-derived neurotrophic factor. J Neurosci 23: 4967-4974, 2003. 
37. Gondi CS, Kandhukuri N, Kondraganti S, Gujrati M, Olivero WC, Dinh DH and Rao JS: Down-regulation of UPAR and cathepsin B retards cofilin dephosphorylation. Int J Oncol 28: 633-639, 2006.

38. Ghadersohi A, Pan D, Fayazi Z, Hicks DG, Winston JS and Li F: Prostate-derived Ets transcription factor (PDEF) downregulates survivin expression and inhibits breast cancer cell growth in vitro and xenograft tumor formation in vivo. Breast Cancer Res Treat (In press).

39. Sloane BF, Yan S, Podgorski I, Linebaugh BE, Cher ML, Mai J, Cavallo-Medved D, Sameni M, Dosescu J and Moin K: Cathepsin B and tumor proteolysis: contribution of the tumor microenvironment. Semin Cancer Biol 15: 149-157, 2005.

40. Dennhofer R, Kurschat P, Zigrino P, Klose A, Bosserhoff A, van MG, Krieg T, Mauch C and Hunzelmann N: Invasion of melanoma cells into dermal connective tissue in vitro: evidence for an important role of cysteine proteases. Int J Cancer 106: 316-323, 2003.

41. Turk B, Turk D and Turk V: Lysosomal cysteine proteases: more than scavengers. Biochim Biophys Acta 1477: 98-111, 2000.

42. Noel A and Foidart JM: [The metalloproteinases in cancer] Bull Mem Acad R Med Belg 160: 417-424, 2005.

43. Kim TD, Song KS, Li G, Choi H, Park HD, Lim K, Hwang BD and Yoon WH: Activity and expression of urokinase-type plasminogen activator and matrix metalloproteinases in human colorectal cancer. BMC Cancer 6: 211, 2006

44. Kayser K, Richter N, Hufnagl P, Kayser G, Kos J and Werle B: Expression, proliferation activity and clinical significance of cathepsin B and cathepsin L in operated lung cancer. Anticancer Res 23: 2767-2772, 2003.

45. Roomi MW, Ivanov V, Kalinovsky T, Niedzwiecki A and Rath M: Inhibition of malignant mesothelioma cell matrix metalloproteinase production and invasion by a novel nutrient mixture. Exp Lung Res 32: 69-79, 2006.

46. Frosch BA, Berquin I, Emmert-Buck MR, Moin K and Sloane BF: Molecular regulation, membrane association and secretion of tumor cathepsin B. APMIS 107: 28-37, 1999.

47. Sameni M, Elliott E, Ziegler G, Fortgens PH, Dennison C and Sloane BF: Cathepsin B and D are localized at the surface of human breast cancer cells. Pathol Oncol Res 1: 43-53, 1995.

48. Sloane BF, Moin K, Sameni M, Tait LR, Rozhin J and Ziegler G: Membrane association of cathepsin B can be induced by transfection of human breast epithelial cells with c-Ha-ras oncogene. J Cell Sci 107: 373-384, 1994

49. Prenzel KL, Monig SP, Sinning JM, Baldus SE, Brochhagen HG, Schneider PM and Holscher AH: Lymph node size and metastatic infiltration in non-small cell lung cancer. Chest 123: 463-467, 2003.

50. Bervar A, Zajc I, Sever N, Katunuma N, Sloane BF and Lah TT: Invasiveness of transformed human breast epithelial cell lines is related to cathepsin $\mathrm{B}$ and inhibited by cysteine proteinase inhibitors. Biol Chem 384: 447-455, 2003.

51. Itoh T, Tanioka M, Matsuda H, Nishimoto H, Yoshioka T, Suzuki R and Uehira M: Experimental metastasis is suppressed in MMP-9-deficient mice. Clin Exp Metastasis 17: 177-181, 1999.

52. Hua J and Muschel RJ: Inhibition of matrix metalloproteinase 9 expression by a ribozyme blocks metastasis in a rat sarcoma model system. Cancer Res 56: 5279-5284, 1996.
53. Peschos D, Damala C, Stefanou D, Tsanou E, Assimakopoulos D Vougiouklakis T, Charalabopoulos K and Agnantis NJ: Expression of matrix metalloproteinase-9 (gelatinase B) in benign, premalignant and malignant laryngeal lesions. Histol Histopathol 21: 603-608, 2006.

54. Jennbacken K, Gustavsson H, Welen K, Vallbo C and Damber JE: Prostate cancer progression into androgen independency is associated with alterations in cell adhesion and invasivity. Prostate 66: 1631-1640, 2006.

55. Olsson R, Maxhuni A and Carlsson PO: Revascularization of transplanted pancreatic islets following culture with stimulators of angiogenesis. Transplantation 82: 340-347, 2006.

56. Luo Y, Zhou H, Krueger J, Kaplan C, Lee SH, Dolman C, Markowitz D, Wu W, Liu C, Reisfeld RA and Xiang R: Targeting tumor-associated macrophages as a novel strategy against breast cancer. J Clin Invest 116: 2132-2141, 2006.

57. Park MJ, Kim MS, Park IC, Kang HS, Yoo H, Park SH, Rhee CH, Hong SI and Lee SH: PTEN suppresses hyaluronic acid-induced matrix metalloproteinase-9 expression in U87MG glioblastoma cells through focal adhesion kinase dephosphorylation. Cancer Res 62: 6318-6322, 2002

58. Choe G, Park JK, Jouben-Steele L, Kremen TJ, Liau LM, Vinters HV, Cloughesy TF and Mischel PS: Active matrix metalloproteinase 9 expression is associated with primary glioblastoma subtype. Clin Cancer Res 8: 2894-2901, 2002.

59. Yao J, Xiong S, Klos K, Nguyen N, Grijalva R, Li P and Yu D: Multiple signaling pathways involved in activation of matrix metalloproteinase-9 (MMP-9) by heregulin-beta1 in human breast cancer cells. Oncogene 20: 8066-8074, 2001

60. Zeigler ME, Chi Y, Schmidt T and Varani J: Role of ERK and JNK pathways in regulating cell motility and matrix metalloproteinase 9 production in growth factor-stimulated human epidermal keratinocytes. J Cell Physiol 180: 271-284, 1999.

61. Lakka SS, Jasti SL, Gondi C, Boyd D, Chandrasekar N, Dinh DH, Olivero WC, Gujrati M and Rao JS: Downregulation of MMP-9 in ERK-mutated stable transfectants inhibits glioma invasion in vitro. Oncogene 21: 5601-5608, 2002.

62. Chung TW, Lee YC and Kim CH: Hepatitis B viral HBx induces matrix metalloproteinase-9 gene expression through activation of ERK and PI-3K/AKT pathways: involvement of invasive potential. FASEB J 18: 1123-1125, 2004.

63. Broker LE, Huisman C, Span SW, Rodriguez JA, Kruyt FA and Giaccone G: Cathepsin B mediates caspase-independent cell death induced by microtubule stabilizing agents in non-small cell lung cancer cells. Cancer Res 64: 27-30, 2004

64. Jacques-Silva MC, Bernardi A, Rodnight R and Lenz G: ERK PKC and PI3K/Akt pathways mediate extracellular ATP and adenosine-induced proliferation of U138-MG human glioma cell line. Oncology 67: 450-459, 2004

65. Bhaskara VK, Sundaram C and Babu PP: pERK, pAkt and pBad: a possible role in cell poliferation and sustained cellular survival during tumorigenesis and tumor progression in ENU induced transplacental glioma rat model. Neurochem Res 31 1163-1170, 2006.

66. Lenz G: The RNA interference revolution. Braz J Med Biol Res 38: 1749-1757, 2005. 